\title{
Intrinsic fluorescence studies of compatibility in thermoplastic phenol formaldehyde resin / poly(e-caprolactone) blends
}

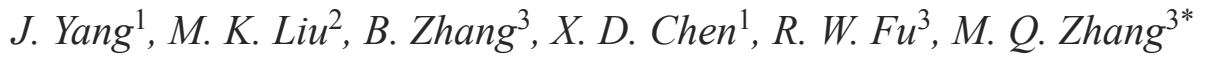 \\ ${ }^{1}$ Institute of Polymer Science, DSAPM Lab, OFCM Institute, School of Chemistry and Chemical Engineering, \\ Sun Yat-sen University, Guangzhou 510275, PR China \\ ${ }^{2}$ School of Light and Chemical Engineering, Guangdong University of Technology, Guangzhou 510006, PR China \\ ${ }^{3}$ Key Laboratory for Polymeric Composite and Functional Materials of Ministry of Education, School of Chemistry and \\ Chemical Engineering, Sun Yat-sen University, Guangzhou 510275, PR China
}

Received 14 November 2010; accepted in revised form 14 February 2011

\begin{abstract}
Intrinsic fluorescence method was applied to study the miscibility and interactions of thermoplastic phenol formaldehyde resin (TPF) / poly( $\varepsilon$-caprolactone) (PCL) blends. The characteristic intrinsic fluorescence emission of TPF at $313 \mathrm{~nm}$ showed the very good sensitivity to monitor the macromolecular chain motion in the TPF/PCL blends. The glass transition $\left(T_{\mathrm{g}}\right)$, crystallization $\left(T_{\mathrm{c}}\right)$, and melting transition point $\left(T_{\mathrm{m}}\right)$ of TPF/PCL blends were measured by the temperature dependence of intrinsic fluorescence intensities upon heating or cooling process. Interestingly, when TPF/PCL $\geq 5 / 5$, besides a $T_{\mathrm{g}}$ for the amorphous phase of blend, another transition at temperature a little higher than $T_{\mathrm{g}}$ of PCL can be observed by intrinsic fluorescence method. This microheterogeneity can be explained by the so-called 'rigid amorphous phase' (RAP) due to the good flexibility and the strong self-association of PCL chains in amorphous phase. Besides, the analysis of the dependence of $T_{\mathrm{g}}$ on the content of PCL suggests that this microheterogeneity can attenuate the interactions between TPF and PCL chains and result in a lowering of $T_{\mathrm{g}} \mathrm{S}$ of blends. In view of the simplicity and sensitivity of measurement as well as affordability of instrument, intrinsic fluorescence proved to be an effective means for characterization of microstructural variation in polymer blends.
\end{abstract}

Keywords: polymer blends and alloys, miscibility, interactions, fluorescence

\section{Introduction}

During the past years, the miscibility and specific interaction of miscible blends involving crystallizable polymers have been topics of intense interest in polymer science because of the strong economic incentives arising from their potential applications [1-4]. On the basis of the crystallizability of the constituents, crystalline/amorphous binary polymer blends are more widely studied because of their simpler crystalline phase relative to crystalline/ crystalline ones [5-14]. And the addition of an amorphous polymer to a crystalline one can modify both the melting $\left(T_{\mathrm{m}}\right)$ and the glass transition temperature $\left(T_{\mathrm{g}}\right)$ of the crystalline polymer and consequently has an important effect on kinetic parameters governing the crystallization process. Therefore, it would be very important to determine the interactions between the amorphous polymer and crystallization regimes. And most of studies on these systems are concerned with dipole-dipole interactions, hydrogen bonding strengths, morphology patterns or crystallization kinetics.

From one experimental point of view, an improvement in the understanding of the correlation between

\footnotetext{
${ }^{*}$ Corresponding author, e-mail: ceszmq@mail.sysu.edu.cn
} (c) BME-PT 
microstructure and interaction of polymers has been obtained by several techniques, such as differential scanning calorimetry (DSC), dynamic mechanical thermal analysis (DMA), electron microscopy (EM), Fourier transform infrared (FTIR) spectroscopy etc. [5-14] Each of these techniques has its advantages and drawbacks. For instance, DSC is very convenient to observe miscibility in polymer blends, but it is not so sensitive and sometimes it is very hard to clearly identify $T_{\mathrm{g}} \mathrm{s}$ of the blends. Though DMA is relatively sensitive [15], the sample preparation is complicated, especially for those polymers whose $T_{\mathrm{g}}$ is below the room temperature. Compared with thermal analysis and EM, FTIR can analyze, in situ, some positive information on specific interactions between polymers without introducing additional physical process like freezing a given phase-separated state for the measurements. However, the IR spectral bands cannot be readily resolved into two peaks with areas corresponding to the free and the hydrogen-bonded absorptions [16]. Relatively, owing to the merits of high sensitivity and nondestructive measurements, the fluorescence technology has been regarded as a powerful and effective tool to measure the macromolecular motions on a molecular level with probe and labeling [17-19]. Although this method can obtain lots of useful information of polymer micromorphology and microstructure, the labeling procedure is often tedious. In addition, in most of the fluorimetric studies of polymer, the fluorescent probe was covalently attached to one of the polymers, which in fact changed the microenvironment of macromolecules and made the macromolecules more hydrophobic, thus enhancing their complexation ability. It is worth noting that the intrinsic fluorescence of polymers has also shown to be highly sensitive to issues ranging from local polymer conformational populations in solution and phase behavior in solvents and polymer blends to local microenvironments in bulk homopolymers [20-23]. Due to its intrinsic sensitivity, this fluorescence method also proved to be powerful in the study of small-scale phase separation and low-concentration miscibility [24]. In our previous researches $[25,26]$, the intrinsic fluorescence spectra were found to be very simple and sensitive means to characterize the transition of molecular conformation and aggregation of macromolecular chains.
In this work, we employed the intrinsic fluorescence method to investigate the miscibility and interactions of crystalline/amorphous polymer blends. For convenience, we chose a very common crystalline polymer, poly( $\varepsilon$-caprolactone) (PCL), which is miscible with several amorphous polymers through the formation of hydrogen bonding [27, 28]. Since the miscibility of PCL blends depends on the self-association and inter-association of hydrogen-bonding donor polymers, the amorphous component used here is thermoplastic phenol formaldehyde resin (TPF) which has polar group (hydroxyl group) and chromophores (benzene rings). It was found that the intrinsic fluorescence can provide us valuable information of compatibility on a very small scale and might supplement the existing characterization tools.

\section{Experimental}

\subsection{Materials and samples preparation}

The PCL used in this work was purchased from Polysciences (UK). The TPF was synthesized as follows: First, the molten phenol and oxalic acid were placed into a flask fitted with a mechanical stirrer, a condenser, and a thermometer. And then the mixture was heated to $90^{\circ} \mathrm{C}$ (a slight exotherm was noted), and formaldehyde was charged into the reaction mixture over a 90 min period using a dropping funnel, during which time the temperature began to drop. The molar ratio for phenol / formaldehyde / oxalic acid was $1 / 0.75 / 0.01$. External heating was required to keep the system at $\sim 95^{\circ} \mathrm{C}$ for the duration of the reaction. Reactions were heated for an additional $6 \mathrm{~h}$ before the resins were isolated. After the condensation process, volatiles, water, and some free phenol were removed using a hightemperature $\left(150^{\circ} \mathrm{C}\right)$ vacuum distillation. Finally, the solid resin was powdered using a mortar and pestle. The molecular weights and the polydispersity index (DPI) were determined through gel permeation chromatography (GPC) using a Waters 510 HPLC (U. S. A.), equipped with a 410 differential refractometer, a refractive index (RI) detector, and three Ultrastyragel columns connected in series in order of increasing pore size. $N, N$-dimethylformamide (DMF) with $\mathrm{LiBr}(1 \mathrm{~g} / \mathrm{l})$ was used as eluent solvent at a flow rate of $0.6 \mathrm{ml} / \mathrm{min}$ at $25^{\circ} \mathrm{C}$. DMF (A. R.) and toluene (A. R.), purchased from Guangzhou Chemical Reagent Factory (P. R. China), 
<smiles>CC(C)(C)Cc1cccc(C(C)(C)C)c1O</smiles>

TPF<smiles>CC(=O)COCCO</smiles>

PCL
Figure 1. Schematic representation of the chemical structure of TPF and PCL molecules

Table 1. Characterization of TPF and PCL used in this study

\begin{tabular}{|l|c|c|c|c|}
\hline Polymer & $\mathbf{M}_{\mathbf{n}}[\mathbf{D a}]^{\mathbf{a}}$ & $\mathbf{D P I}$ & $\mathbf{T}_{\mathbf{g}}[\mathbf{K}]^{\mathbf{b}}$ & $\mathbf{T}_{\mathbf{m}}[\mathbf{K}]^{\mathbf{b}}$ \\
\hline TPF & $1 \cdot 10^{3}$ & 1.9 & 337 & - \\
\hline PCL & $4 \cdot 10^{4}$ & 1.5 & 210 & 327 \\
\hline
\end{tabular}

${ }^{\text {aD }}$ ata obtained from GPC measurement

${ }^{\mathrm{b}}$ Determined by DSC method

were distilled under reduced pressure before use. The chemical structures and basic characterization of TPF and PCL are shown in Figure 1 and Table 1, respectively. Film samples with various compositions were prepared by casting from $1 \mathrm{wt} \%$ toluene solutions onto quartz plates at room temperature. Firstly, the solution was allowed to evaporate slowly at room temperature for 1 day, and then the films were further heat treated in a vacuum oven at $50^{\circ} \mathrm{C}$ for $24 \mathrm{~h}$ to ensure the total elimination of solvent.

\subsection{Apparatus}

The fluorescence spectra were recorded with a FLS920 Combined Fluorescence Lifetime and Steady State Spectrometer (Edinburgh, England) using either a cooling or heating rate of $3 \mathrm{~K} / \mathrm{min}$. Unless otherwise specified, in cooling and heating measurements, the fluorescence spectra were recorded after having annealed samples at 410 and $180 \mathrm{~K}$ for $15 \mathrm{~min}$, respectively. To minimize the influence of reflected light, $45^{\circ}$-angle sample geometry was employed. For the convenience of comparison, samples were also examined by a DSC-204 (Netzsch, Germany) under the same condition.

\section{Results and discussion}

\subsection{Intrinsic fluorescence of TPF and PCL solutions.}

In order to better understand the intrinsic fluorescence of blend films, we first measured the emission spectra in TPF and PCL solution at the concentration of $2 \mathrm{~g} / \mathrm{l}$. Clearly, a negligible fluorescence emission of PCL can be seen in Figure 2. Besides, there exists the maximum fluorescence intensity for

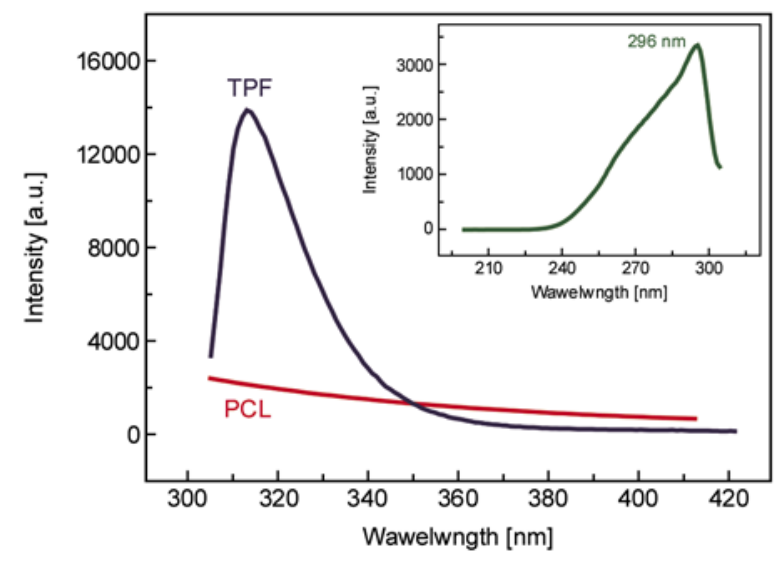

Figure 2. Fluorescence emission spectra of TPF and PCL solution $(C=2 \mathrm{~g} / \mathrm{l})$ in THF $\left(\lambda_{\mathrm{ex}}=296 \mathrm{~nm}\right)$. Inset shows the excitation spectrum for phenolic film.

TPF at $315 \mathrm{~nm}$ when excitation was done at $296 \mathrm{~nm}$ according to the excitation spectrum shown in the inset of Figure 2. Thus, these results make it easy to attribute the fluorescence emission of TPF/PCL films in the following discussions.

\subsection{Temperature dependent intrinsic fluorescence of TPF/PCL Films}

Figure 3 shows the intrinsic fluorescence spectra of TPF/PCL (3/7) blend film at various temperatures during the cooling process. As expected, a maximum intensity can be observed at about $313 \mathrm{~nm}$, indicative of the emission of TPF phase. Obviously, the emission intensity increases as the temperature decreases, suggesting a decrease in the non-radiative deactivation process upon cooling.

Figure 4 presents the temperature dependence of fluorescence intensity of TPF/PCL (3/7) blend film during the cooling process. It can be clearly seen that two crossovers are located at 241 and $298 \mathrm{~K}$,

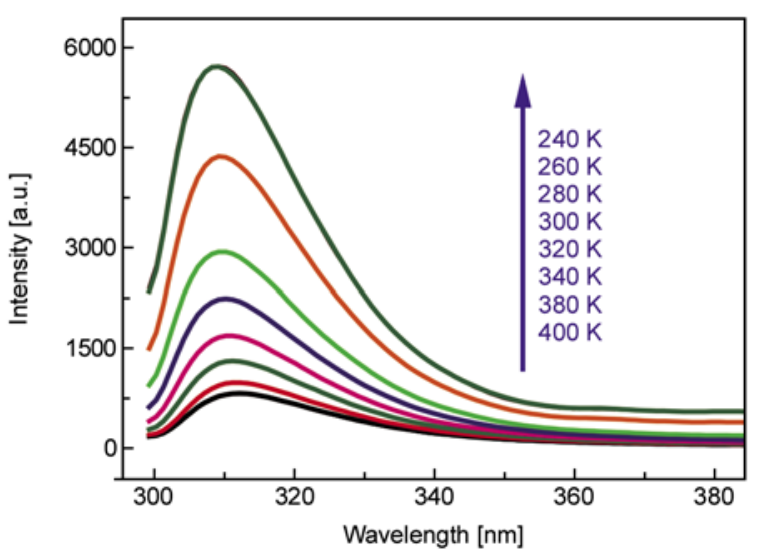

Figure 3. Intrinsic fluorescence spectra of TPF/PCL (3/7) blend film at various temperatures during the cooling process 


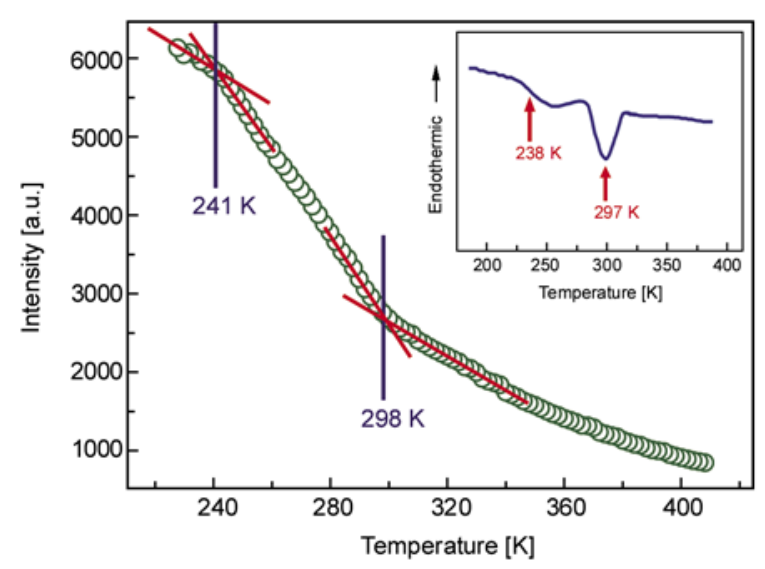

Figure 4. Temperature dependence of the intrinsic fluorescence intensity for TPF/PCL (3/7) blend film during the cooling process. The inset shows the DSC cooling trace.

respectively, which are in good agreement with the transition temperatures shown in DSC cooling trace, i.e., 238 and $297 \mathrm{~K}$, respectively (see inset of Figure 4). Thus, these two crossovers should be attributed to the glass transition temperature $\left(T_{\mathrm{g}}\right)$ of TPF/PCL amorphous phase and the crystallization temperature $\left(T_{\mathrm{c}}\right)$ of PCL crystalline phase, respectively. Such single $T_{\mathrm{g}}$ obtained by both fluorescence and DSC methods indicates that TPF/PCL (3/7) blend is fully miscible in the amorphous region.

Before we present a further interpretation of the temperature dependence of fluorescence intensity shown in Figure 4, it is necessary to review briefly several aspects of the photophysical process. Fundamentally, the excited state of chromophore promoted by absorption of a photon is deactivated by radiative (fluorescence $K_{\mathrm{r}}$ ), and non-radiative $\left(K_{\mathrm{nr}}\right)$, thus the fluorescence intensity $(I)$ can be understood as Equation (1):

$$
I \propto \varphi_{\mathrm{F}}=\frac{K_{\mathrm{r}}}{K_{\mathrm{r}}+K_{\mathrm{nr}}}
$$

where $\varphi_{\mathrm{F}}$ is the fluorescence quantum yield. Since $\mathrm{Kr}$ only depends on temperature through the refraction index [29], Equation (1) can be expressed as Equation (2):

$$
I \propto \frac{K_{\mathrm{r}}^{0} n^{2}}{K_{\mathrm{r}}^{0} n^{2}+K_{\mathrm{nr}}}=1-\frac{K_{\mathrm{nr}}}{K_{\mathrm{r}}^{0} n^{2}+K_{\mathrm{nr}}}
$$

where $K_{\mathrm{r}}^{0}$ is a constant independent of temperature and $n$ is the refraction index. Distinctly, as shown in Equation (2), the intrinsic fluorescence intensity is mainly influenced by $n$ and $K_{\text {nr }}$. Usually, it is assumed that, the non-radiative processes $\left(K_{\mathrm{nr}}\right)$ almost become zero at very low temperatures, so that the radiative deactivation is the favored pathway and only $K_{\mathrm{r}}$ accounts for the fluorescence intensity. However, at relatively high temperatures, the motions of the polymer chains are less limited and the balance of these two factors should be taken into account: (i) the reduction of the refraction index [30] and (ii) the deactivation of the fluorescence by non-radiative processes due to the increased thermal motions [31]. Note that, the refractive index of amorphous polymer film decreases with the temperature increases and shows a inflection point at $T \mathrm{~g}$, suggesting stronger temperature dependence at $T>T_{\mathrm{g}}$ than $T<T_{\mathrm{g}}[30]$. Hence, the explanation of the results obtained in Figure 4 should now be clear. When the temperature was lower than $298 \mathrm{~K}$ $\left(T<T_{\mathrm{c}}\right)$, the molecular chains of PCL started to arrange themselves in regular arrays upon crystallization and restrict the motions of TPF chains which reduced the non-radiative decay rate and finally caused the higher fluorescence quantum yield and the greater temperature dependence of intrinsic fluorescence intensity. On the other hand, the less temperature dependence of intrinsic fluorescence intensity at $T<241 \mathrm{~K}$ was dominantly induced by the effect of refraction index and nonradiative rate, which both showed less temperature dependence in the glassy state compared to rubbery state [32], due to the limited large-scale cooperative mobility of macromolecular chains in amorphous region at $T<T_{\mathrm{g}}$.

To obtain the comprehensive assessment of intrinsic fluorescence, the heating process of TPF/PCL (3/7) blend film has also been studied, shown in Figure 5. There are also two obvious crossovers in the plot, located at 248 and $318 \mathrm{~K}$, highly consistent with the $T_{\mathrm{g}}$ of TPF/PCL amorphous phase $(245 \mathrm{~K})$ and the melting temperature $\left(T_{\mathrm{m}}\right)$ of PCL crystalline phase $(319 \mathrm{~K})$ obtained by DSC method (see inset of Figure 5). As expected, the temperature dependence of fluorescence intensity around $T_{\mathrm{g}}$ of TPF/ PCL amorphous phase during cooling process (Figure 4) is similar with that during heating process (Figure 5). However, in contrast to cooling process, the heating process shows an opposite intensity variance around the transition temperature of PCL crystalline, that is, a stronger temperature dependence of fluorescence intensity. This behavior sug- 


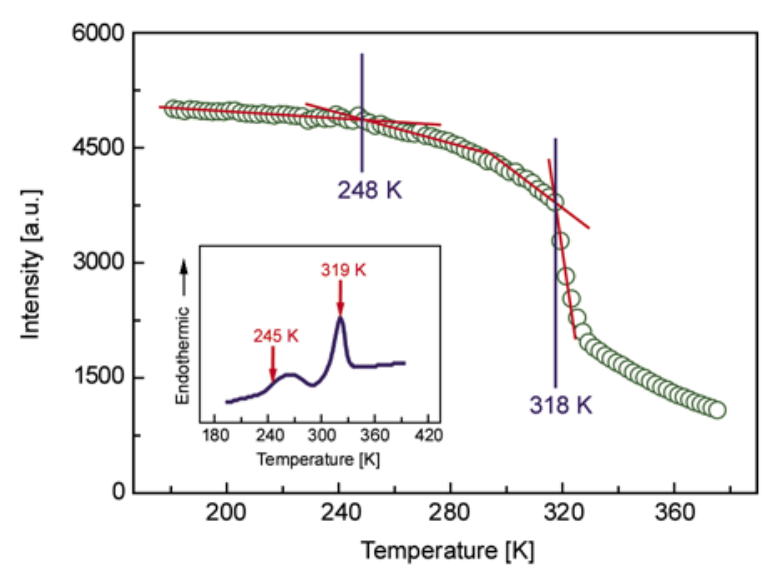

Figure 5. Temperature dependence of the intrinsic fluorescence intensity for TPF/PCL (3/7) blend film during the heating process. The inset shows the DSC heating trace.

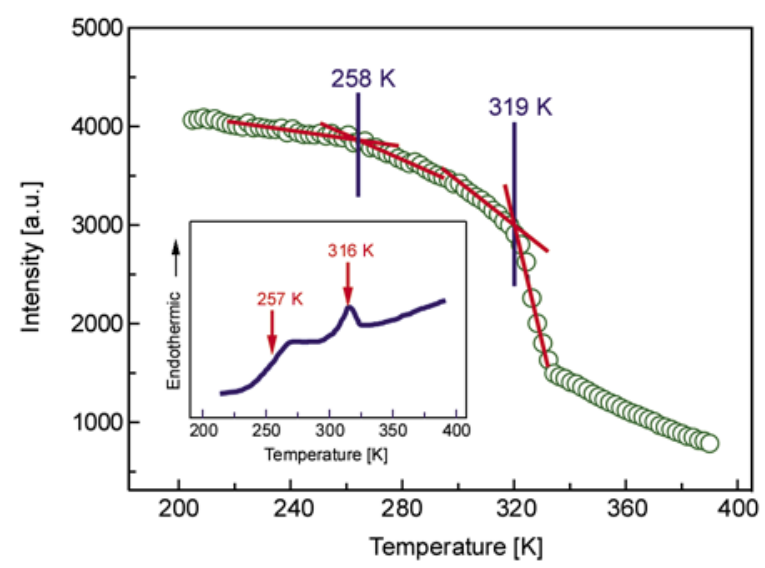

Figure 6. Temperature dependence of the intrinsic fluorescence intensity for TPF/PCL (4/6) blend film during the heating process. The inset shows the DSC heating trace.

gests that, when melting process started to occur, the flexible PCL chains could render more drastic movement of TPF due to the strong hydrogen bond interaction between the hydroxyls of TPF and carbonyls of PCL, which greatly increased the nonradiative decay rate and thus reduced intrinsic fluorescence quantum yield of TPF. Thus, the results in Figure 5 not only verify our explanation in Figure 4, but also strongly suggest that the intrinsic fluorescence is very sensitive method for monitoring the molecular chain motions in TPF/PCL blend film. The similar behavior can be also found in the case of TPF/PCL (4/6) blend (see Figure 6).

However, it can be seen for TPF/PCL (5/5) blend, there is only a single $T_{\mathrm{g}}(263 \mathrm{~K})$ in the DSC trace (inset of Figure 7), which indicates the TPF/PCL $(5 / 5)$ blend is not only completely amorphous but

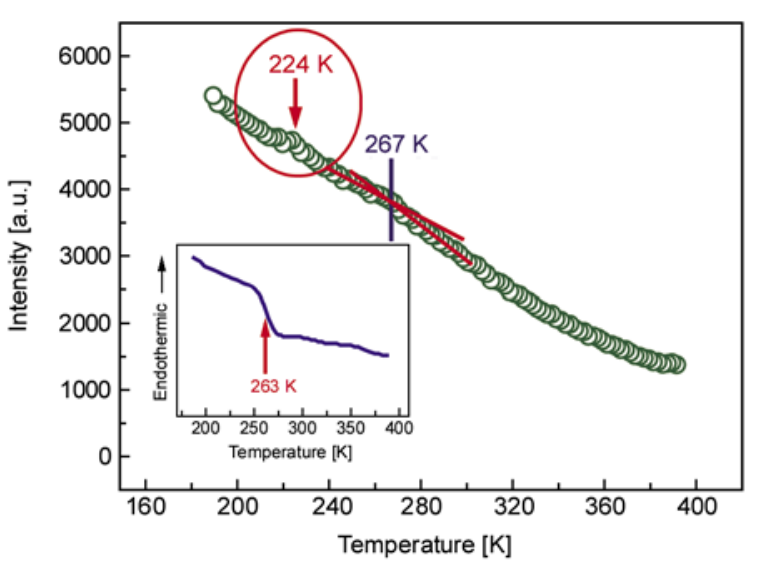

Figure 7. Temperature dependence of the intrinsic fluorescence intensity for TPF/PCL (5/5) blend film during the cooling process. The inset shows the DSC cooling trace.

also homogeneous due to the strong hydrogen bond interaction. Surprisingly, as shown in Figure 7, it can be observed that there are two crossovers determined by intrinsic fluorescence, located at 267 and $224 \mathrm{~K}$, respectively. The former temperature is in agreement with $T_{\mathrm{g}}$ of TPF/PCL blend in DSC trace, while the latter one is a little higher than the $T_{\mathrm{g}}$ of PCL $(210 \mathrm{~K})$. Generally, a polymer blend is regarded as miscible when it exhibits a single $T_{\mathrm{g}}$ and regarded as immiscible when it exhibits two $T_{\mathrm{g}} \mathrm{s}$ corresponding to those of the constituent components as determined by DSC. However, there is a general consensus that such experimental technique, while very useful to investigate macrophase separation in the polymer blends, cannot guarantee that a polymer blend is miscible on a molecular level [33-35]. Besides, fluorescence spectroscopy has proven to be very sensitive method in studying aggregation and phase separation behavior at the molecular level, and can provide us with information on a scale smaller than conventional light scattering and comparable to small-angle neutron scattering (SANS) [36]. Since the homogeneity of a polymer blend is usually dependent on the detectable minimum domain size by the experimental technique used, a plausible explanation is that, the crossover at $224 \mathrm{~K}$ may be ascribed to the microscopic heterogeneity in the TPF/PCL (5/5) blend.

Note, in Figure 7, that there is a slight change in the slope at around $320 \mathrm{~K}$ which is close to the $T_{\mathrm{c}}$ of PCL. Was this caused by the inhomogeneous mixing in sample preparation? To answer this question, Figure 8 displayed the temperature dependence of 


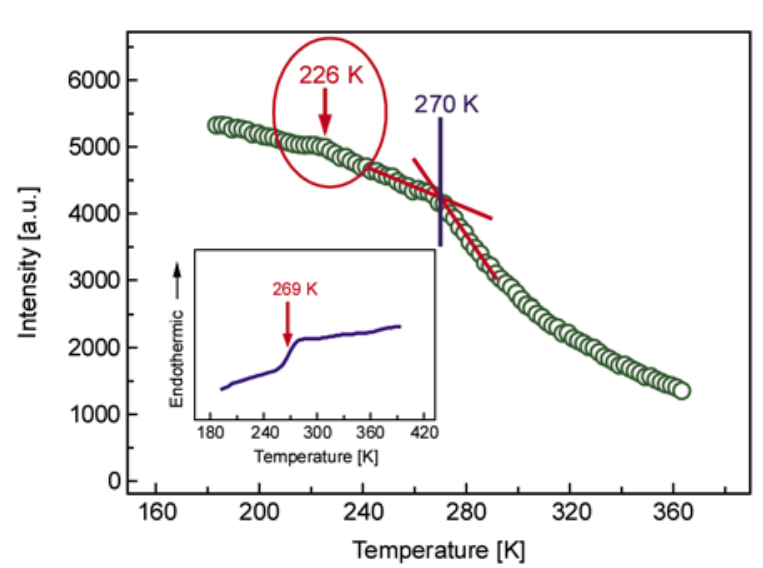

Figure 8. Temperature dependence of the intrinsic fluorescence intensity for TPF/PCL (5/5) blend film during the heating process. The inset shows the DSC heating trace.

the intrinsic fluorescence intensity for TPF/PCL $(5 / 5)$ blend film during the heating process. Clearly, the inflexion point at $270 \mathrm{~K}$ can be observed, which is ascribed to the $T_{\mathrm{g}}$ of TPF/PCL blend. However, another unexpected crossover at $226 \mathrm{~K}$ has also been found. Moreover, no drastic decrease in the slope appears around $T_{\mathrm{m}}$ of PCL in Figure 8. This result strongly convinces us that the crossover at lower temperature (224 K) in Figure 7 should result from the microheterogeneity in the TPF/PCL (5/5) blend instead of the error in sample preparation.

In order to further testify the above result, TPF-rich blend has also been investigated. Because the intrinsic fluorescence showed the more obvious response upon heating than upon cooling, we only concentrate on the temperature dependence of fluorescence intensity of TPF/PCL (6/4) and (7/3) blend film during the heating process, shown in Figure 9 and 10, respectively. Similarly, no indication of PCL crystalline but two transition temperatures appear (one close to $T_{\mathrm{g}}$ of blend and the other a little higher than $T_{\mathrm{g}}$ of PCL), which coincides with the result shown in Figure 7 and 8.

To better understand the compatibility of TPF/PCL, a careful analysis of the dependence of $T_{\mathrm{g}}$ for polymer blends on the content of PCL was considered. As we know, the Fox relation [37, 38] (see Equation (3)) is well used to describe the $T_{\mathrm{g}}$ dependence of random mixed polymer blend:

$$
\frac{1}{T_{\mathrm{g}}}=\frac{W_{1}}{T_{\mathrm{g} 1}}+\frac{W_{1}}{T_{\mathrm{g} 2}}
$$

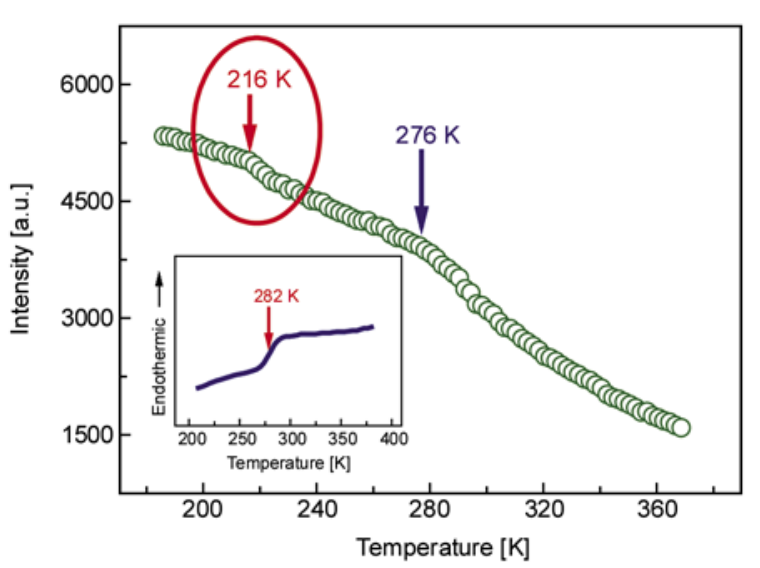

Figure 9. Temperature dependence of the intrinsic fluorescence intensity for TPF/PCL (6/4) blend film during the heating process. The inset shows the DSC heating trace.

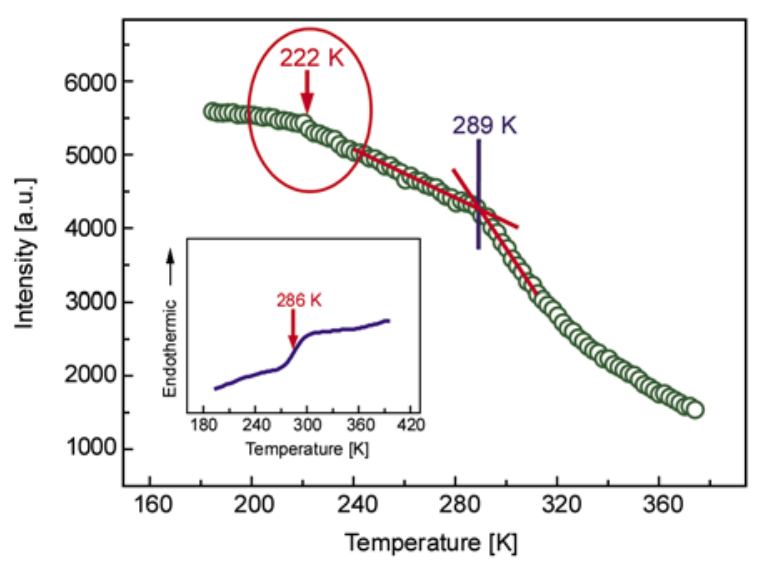

Figure 10. Temperature dependence of the intrinsic fluorescence intensity for TPF/PCL (7/3) blend film during the heating process. The inset shows the DSC heating trace.

where $T_{\mathrm{g} 1}, T_{\mathrm{g} 2}$ and $T_{\mathrm{g}}$ refer to the $T_{\mathrm{g}}$ of TPF, PCL and TPF/PCL blend, $W_{1}$ and $W_{2}$ refer to weight fractions of component, i.e. TPF and PCL, respectively. Figure 11 summarizes the variation of $T_{\mathrm{g}}$ by the intrinsic fluorescence and DSC with increasing $W_{1}$ of TPF/PCL blends. As can be seen, results obtained by intrinsic fluorescence and DSC method show a good agreement. In order to better understand Figure 11, the curves are divided into three regions by two critical weight fractions $W_{\mathrm{cr} 1}$ and $W_{\text {cr2 }}$, which are located at 0.5 and 0.7 , respectively. Obviously, an upward curvature of $T_{\mathrm{g}}-W_{1}$, i.e. strong positive deviations from Fox rule can be seen at $W_{1}<W_{\mathrm{cr} 2}$ (region I and region II). Note that, only DSC data are shown at $W_{2}<W_{\text {crl }}$ (region I) since it is hard for intrinsic fluorescence method to calculate the weight fraction of amorphous component when there exist a crystallization phase in 


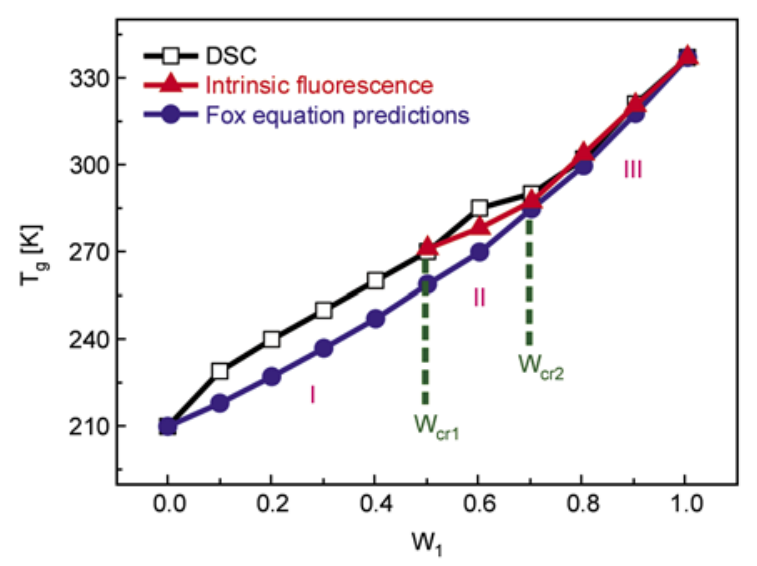

Figure 11. Dependence of $T_{\mathrm{g}}$ obtained by intrinsic fluorescence and DSC on weight fraction of TPF, $W_{1}$, for TPF/PCL blends.

TPF/PCL blends. Since there is no microheterogeneity in region I, the positive deviations can be simply explained by the balance of two opposite effects: (i) the increase in stiffness due to strong interactions between two components which enhances $T_{\mathrm{g}} \mathrm{s}$ of blends [39-41], and (ii) the destruction of the self association of each component which lowers $T_{\mathrm{g}}$ of blends [42]. So it is easy to understand the former effect is the dominant one in region I. Besides, this result also implies that the strong interactions between the TPF and PCL chains can still exist even when the content of TPF is relatively low, e.g. $W_{1}<0.3$. Thereby, it is reasonable to expect that the similar situation should also arise when the content of TPF is high, e.g. $W_{2}>0.7$. Unfortunately, when the content of TPF increases up to $W_{\mathrm{cr} 2}\left(W_{1}=0.7\right)$, the upward curvature disappears (region III). As we know, for the amorphous phase in TPF/PCL blends, the only difference between region I and region III is that there is the microheterogeneity in the latter but not in the former. Thus, the phenomenon in region III not only confirms the existence of microheterogeneity but also suggests this microheterogeneity can attenuate the interactions between TPF and PCL chains and result in a lowering of $T_{\mathrm{g}} \mathrm{s}$ of blends.

\subsection{The mechanism of formation of microheterogeneity}

According to the finding above, a hypothetical mechanism is schematically proposed in Figure 12, to describe the interaction behavior and formation of microheterogeneity in TPF/PCL blends: (i) when TPF/PCL $<5 / 5$, the blend can form a homogeneous amorphous phase and a crystalline phase due to the strong hydrogen bond interactions between the hydroxyls of TPF and the carbonyl or ether groups of PCL; (ii) when TPF/PCL > 5/5, the regular arrangement of PCL macromolecular chain in the crystalline phase is completely destroyed by a large amount of TPF chains. It is worth mentioning that many semi-crystalline polymers such as poly(ethylene terephtahlate) (PET) [43], poly (cabonate) (PC) [44], polypropylene (PP) [45], have been found to possess of in a three-phase structure consisting of crystalline, amorphous phases and a so-called third phase i.e., rigid amorphous phases (RAP). The RAP has the distinct chain mobility from conventional amorphous phase and can only unfreeze at a temperature higher than $T_{\mathrm{g}}$ [46]. Thus, similarly in the cases of TPF/PCL $>5 / 5$, due to their good flexibility and the strong self-association, the amorphous PCL phase still tend to arrange orderly to some extent in a small domain, forming an amorphous PCL microphase like RAP and leading to the microheterogeneity. Similar phenomena have also been observed in other miscible crystalline/amorphous polymer blends judging from the DSC and morphological results. For example, by using ${ }^{1} \mathrm{H}$ spin-lattice relaxation times in the rotating and laboratory frames, Parizel et al. [47] found that, the organization of the PEO/PMMA blend consisted of three parts: a crystalline PEO, constrained PEO units in the neighborhood of the crystalline lamellae and a miscible amorphous phase that is PMMA-rich. In addition, Asano et al. [48] have successfully utilized high-resolution solid-state NMR to analyze various heterogeneity scales in blends of poly

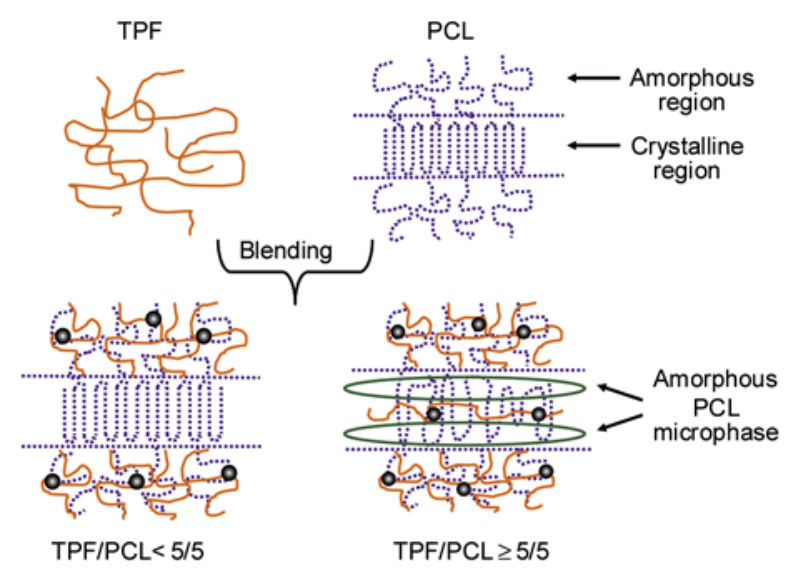

Figure 12. Schematic representation for the heterogeneity in TPF/PCL blends. The solid round dots stand for hydrogen bonds between TPF and PCL. 
(vinylphenol) with poly(ethylene oxide) (PEO), leading to the conclusion that miscibility is limited to above the $20-30 \mathrm{~nm}$ scale. Furthermore, in the research of Lin et al. [49], the rotating-frame spinlattice relaxation time for protons, $T_{1 \rho}\left({ }^{1} \mathrm{H}\right)$, was measured from ${ }^{13} \mathrm{C} \mathrm{CP} / \mathrm{MAS} / \mathrm{DD}$ NMR to probe molecular scales of heterogeneity in the miscible poly(benzyl methacrylate) (PBzMA)/poly(ethylene oxide) (PEO) blend over the whole composition range. Their results indicated that, three phases also appeared for the blends with PEO component $>16 \%$, containing one miscible homogenous PBzMA-rich phase, one constrained PEO phase and one crystalline PEO phase. It worth mentioning, what a pity it is that the unambiguous clarification of PCL micro-phase structure in TPF/PCL blend is now not attainable due to the limitation of the detectable minimum domain size of our existing equipments. However, this work is still in progress in our laboratory by using other model polymer systems with the fluorescent probe technique.

\section{Conclusions}

The miscibility and interactions in TPF/PCL blends were investigated by the intrinsic fluorescence method. By monitoring characteristic intrinsic fluorescence intensity of TPF, the microheterogeneity can be observed in the blends (TPF/PCL $\geq 5 / 5$ ). Such a behavior is because that, after the crystalline phase of PCL is completely destroyed by TPF chains, the amorphous PCL phase still tend to arrange orderly to some extent in a small area due to their good flexibility and the strong self-association and thus forms the RAP. Besides, the analysis of the dependence of $T_{\mathrm{g}}$ on the content of PCL suggests that this microheterogeneity can attenuate the interactions between TPF and PCL chains and result in a lowering of $T_{\mathrm{g}} \mathrm{s}$ of blends. In view of the simplicity and sensitivity of measurement, affordability and availability of instrument, intrinsic fluorescence method proved to be an effective means for characterization of microstructural variation in polymer blends.

Since the molecular weight of TPF is low and the TPF molecules are very easy to diffuse in the blend, whether or not the microheterogeneity behavior obtained in this work can be extended to high-mol- ecular-weight polymers deserves further verification. And we believe that deeper information on the molecular level would be obtained by changing the various chromophores. Besides, the intrinsic fluorescence method can also be extended to applied researches, like in-situ inspection of macromolecular motion, diffusing process, phase separation mechanism, the interfacial interaction between polymers and evaluation of the effect of compatibilizer.

\section{Acknowledgements}

X. D. Chen acknowledges the financial support from the program of National Natural Science Foundation of China (Grant no. 50973129), Natural Science Foundation of Guangdong province (Grant no. 07003702) and China Postdoctoral Science Foundation (Grant no. 20100470953).

\section{References}

[1] Zhong Z., Guo Q., Mi Y.: Solid-state n.m.r. investigation of crosslinkable blends of novolac and poly $(\varepsilon-$ caprolactone). Polymer, 40, 27-33 (1998). DOI: $10.1016 / \mathrm{S} 0032-3861(98) 00242-0$

[2] Miyoshi T., Takegoshi K., Hikichi K.: High-resolution solid-state ${ }^{13} \mathrm{C}$ nuclear magnetic resonance study of a polymer complex: poly(methacrylic acid)/poly(ethylene oxide). Polymer, 37, 11-18 (1996). DOI: $10.1016 / 0032-3861(96) 81594-1$

[3] Chu P. P., Wu H-D.: Solid state NMR studies of hydrogen bonding network formation of novolac type phenolic resin and poly(ethylene oxide) blend. Polymer, 41, 101-109 (1999).

DOI: 10.1016/S0032-3861(99)00098-1

[4] Sawatari C., Kondo T.: Interchain hydrogen bonds in blend films of poly(vinyl alcohol) and its derivatives with poly(ethylene oxide). Macromolecules, 32, 19491955 (1999).

DOI: $10.1021 / \mathrm{ma9809000}$

[5] Russell T. P., Ito H., Wignall G. D.: Neutron and X-ray scattering studies on semicrystalline polymer blends. Macromolecules, 21, 1703-1709 (1988).

DOI: $10.1021 / \mathrm{ma} 00184 \mathrm{a} 029$

[6] Defieuw G., Groeninckx G., Reynaers H.: Miscibility and morphology of binary polymer blends of polycaprolactone with solution-chlorinated polyethylenes. Polymer, 30, 595-603 (1989). DOI: 10.1016/0032-3861(89)90141-9

[7] Talibuddin S., Runt J., Liu L-Z., Chu B.: Microstructure development and crystallization of poly(ethylene oxide) and melt-miscible PEO blends. Macromolecules, 31, 1627-1634 (1998). DOI: $10.1021 / \mathrm{ma971265+}$ 
[8] Penning J. P., st. John Manley R.: Miscible blends of two crystalline polymers. 1 . Phase behavior and miscibility in blends of poly(vinylidene fluoride) and poly (1,4-butylene adipate). Macromolecules, 29, 77-83 (1996).

DOI: $10.1021 / \mathrm{ma950651t}$

[9] Eersels K. L. L., Groeninckx G., Koch M. H. J., Reynaers H.: Influence of transreaction processes on the morphology of semicrystalline aliphatic/aromatic polyamide blends. Polymer, 39, 3893-3900 (1998).

DOI: 10.1016/S0032-3861(97)10092-1

[10] Huo P. P., Cebe P., Capel M.: Dynamic mechanical relaxation and X-ray scattering study of poly(butylene terephthalate)/polyarylate blends. Macromolecules, 26, 4275-4282 (1993).

DOI: $10.1021 / \mathrm{ma} 00068 \mathrm{a} 031$

[11] Cheung Y. W., Stein R. S., Lin J. S., Wignall G. D.: Small-angle scattering investigations of poly( $\varepsilon$-caprolactone)/polycarbonate blends. 2. Small-angle X-ray and light scattering study of semicrystalline/semicrystalline and semicrystalline/amorphous blend morphologies. Macromolecules, 27, 2520-2528 (1994). DOI: $10.1021 / \mathrm{ma} 00087 \mathrm{a} 021$

[12] Saito H., Stuehn B.: Exclusion of noncrystalline polymer from the interlamellar region in poly(vinylidene fluoride)/poly(methyl methacrylate) blends. Macromolecules, 27, 216-218 (1994).

DOI: $10.1021 / \mathrm{ma} 00079 \mathrm{a} 032$

[13] Sadocco P., Canetti M., Seves A., Martuscelli E.: Small-angle X-ray scattering study of the phase structure of poly(D-(-)-3-hydroxybutyrate) and atactic poly(epichlorohydrin) blends. Polymer, 34, 33683375 (1993).

DOI: 10.1016/0032-3861(93)90462-J

[14] Liu L-Z., Chu B., Penning J. P., Manley R. S. J.: A synchrotron SAXS study of miscible blends of semicrystalline poly(vinylidene fluoride) and semicrystalline poly(1,4-butylene adipate). Macromolecules, 30, 43984404 (1997).

DOI: $10.1021 / \mathrm{ma961719n}$

[15] Molnar A., Eisenberg A.: Miscibility of polyamide-6 with lithium or sodium sulfonated polystyrene ionomers. Macromolecules, 25, 5774-5782 (1992).

DOI: $10.1021 / \mathrm{ma} 00047 \mathrm{a} 032$

[16] Le Menestrel C., Bhagwagar D. E., Painter P. C., Coleman M. M., Graf J. F.: Hydrogen bonding in ternary polymer blend systems: Determination of association parameters. Macromolecules, 25, 7101-7106 (1992). DOI: 10.1021/ma00052a005

[17] Klopffer M-H., Bokobza L., Monnerie L.: Structural side effects in the use of a fluorescent probe for monitoring polymer mobility. Macromolecules, 31, 82918296 (1998).

DOI: $10.1021 / \mathrm{ma9} 00717 \mathrm{~V}$
[18] Moffitt M., Farinha J. P. S., Winnik M. A., Rohr U., Müllen K.: Steady-state and dynamic fluorescence measurements of a perylene-labeled triblock copolymer: Evidence for ground-state dye aggregate formation. Macromolecules, 32, 4895-4904 (1999).

DOI: $10.1021 / \mathrm{ma990332 \textrm {s }}$

[19] Corrales T., Peinado C., Bosch P., Catalina F.: Study of secondary relaxations of poly(ethylene terephthalate) by photoluminescence technique. Polymer, 45, 15451554 (2004).

DOI: 10.1016/j.polymer.2003.12.051

[20] Major M. D., Torkelson J. M.: Fluorescence of vinyl aromatic polyelectrolytes: Effects of conformation, concentration, and molecular weight of sodium poly (styrene sulfonate). Macromolecules, 19, 2801-2806 (1986).

DOI: $10.1021 / \mathrm{ma} 00165 \mathrm{a} 024$

[21] Tsai F. J., Torkelson J. M.: Phase separation of oligomeric polystyrene-polybutadiene blends as studied by excimer fluorescence. Macromolecules, 21, 1026-1033 (1988).

DOI: $10.1021 / \mathrm{ma} 00182 \mathrm{a} 031$

[22] Clauss B., Salem D. R.: A chain-intrinsic fluorescence study of orientation-strain behavior in uniaxially drawn poly(ethylene terephthalate) film. Macromolecules, 28, 8328-8333 (1995).

DOI: $10.1021 / \mathrm{ma} 00128 \mathrm{a} 049$

[23] Sanz A., Mendicuti F.: Excimers in dilute solutions of $N$-vinyl carbazole/styrene copolymers of different molar compositions. Polymer, 43, 6123-6130 (2002). DOI: $10.1016 / \mathrm{S} 0032-3861(02) 00584-0$

[24] Semerak S. N., Frank C. W.: Excimer fluorescence as a molecular probe of blend miscibility. 3. Effect of molecular weight of the host matrix. Macromolecules, 14, 443-449 (1981). DOI: $10.1021 / \mathrm{ma} 50003 \mathrm{a} 039$

[25] Luo W-A., Liao Z., Yan J., Li Y., Chen X., Mai K., Zhang M.: Cold-crystallization of poly(trimethylene terephthalate) studied by photoluminescence of its amorphous portion. Macromolecules, 41, 7513-7518 (2008).

DOI: $10.1021 / \mathrm{ma} 801119 \mathrm{n}$

[26] Luo W-A., Chen Y., Chen X., Liao Z., Mai K., Zhang M.: Photoinduced energy transfer in poly(trimethylene terephthalate). Macromolecules, 41, 3912-3918 (2008). DOI: $10.1021 / \mathrm{ma} 8000059$

[27] Lezcano E. G., Coll C. S., Prolongo M. G.: Melting behaviour and miscibility of poly( $\varepsilon$-caprolactone $)+$ poly(4-hydroxystyrene) blends. Polymer, 37, 36033609 (1996).

DOI: $10.1016 / 0032-3861(96) 00170-X$

[28] De Juana R., Cortazar M.: Study of the melting and crystallization behavior of binary poly $(\varepsilon$-caprolactone)/poly(hydroxy ether of bisphenol A) blends. Macromolecules, 26, 1170-1176 (1993).

DOI: $10.1021 / \mathrm{ma} 00057 \mathrm{a} 042$ 
[29] Birks J. B.: Photophysics of aromatics molecules. Wiley, New York (1970).

[30] Beaucage G., Composto R., Stein R. S.: Ellipsometric study of the glass transition and thermal expansion coefficients of thin polymer films. Journal of Polymer Science Part B: Polymer Physics, 31, 319-326 (1993). DOI: $10.1002 /$ polb.1993.090310310

[31] Turrión S. G., Olmos D., Ekizoglou N., GonzálezBenito J.: Fluorescence response from anthracene labeled polystyrene to study its thermal transitions. Polymer, 46, 4023-4031 (2005). DOI: 10.1016/j.polymer.2005.03.056

[32] Mundra M. K., Ellison C. J., Behling R. E., Torkelson J. M.: Confinement, composition, and spin-coating effects on the glass transition and stress relaxation of thin films of polystyrene and styrene-containing random copolymers: Sensing by intrinsic fluorescence. Polymer, 47, 7747-7759 (2006). DOI: $10.1016 /$ j.polymer.2006.08.064

[33] Wagler T., Rinaldi P. L., Han C. D., Chun H.: Phase behavior and segmental mobility in binary blends of polystyrene and poly(vinyl methyl ether). Macromolecules, 33, 1778-1789 (2000).

DOI: $10.1021 / \mathrm{ma} 9909105$

[34] Kuo S. W., Huang C. F., Chang F. C.: Study of hydrogen-bonding strength in poly( $\varepsilon$-caprolactone) blends by DSC and FTIR. Journal of Polymer Science Part B: Polymer Physics, 39, 1348-1359 (2001).

DOI: $10.1002 /$ polb.1107

[35] Stoelting J., Karasz F. E., MacKnight W. J.: Dynamic mechanical properties of poly(2,6-dimethyl-1,4-phenylene ether)-polystyrene blends. Polymer Engineering and Science, 10, 133-138 (1970).

DOI: $10.1002 /$ pen.760100302

[36] Gomez-Elvira J. M., Halary J. L., Monnerie L., Fetters L. J.: Isotope effects on the phase separation in polystyrene-poly(vinyl methyl ether) blends. 2. Influence of the microstructure of linear and star block copolymers. Macromolecules, 27, 3370-3375 (1994).

DOI: $10.1021 / \mathrm{ma} 00090 \mathrm{a} 035$

[37] Prolongo M. G., Salom C., Masegosa R. M.: Glass transitions and interactions in polymer blends containing poly(4-hydroxystyrene) brominated. Polymer, 43, 93-102 (2001).

DOI: 10.1016/S0032-3861(01)00567-5

[38] Fox T. G.: Influence of diluent and of copolymer composition on the glass temperature of a polymer system. Bulletin of the American Physical Society, 1, 123-124 (1956).

[39] Kwei T. K.: The effect of hydrogen bonding on the glass transition temperatures of polymer mixtures. Journal of Polymer Science, Polymer Letters Edition, 22, 307-313 (1984). DOI: $10.1002 /$ pol.1984.130220603
[40] Prinos A., Dompros A., Panayiotou C.: Thermoanalytical and spectroscopic study of poly(vinyl pyrrolidone)/poly(styrene-co-vinyl phenol) blends. Polymer, 39, 3011-3016 (1998).

DOI: $10.1016 / \mathrm{S} 0032-3861(97) 10085-4$

[41] Wang J., Cheung M. K., Mi Y.: Miscibility in blends of poly (4-vinylpyridine)/poly (4-vinylphenol) as studied by ${ }^{13} \mathrm{C}$ solid-state NMR. Polymer, 42, 3087-3093 (2001).

DOI: 10.1016/S0032-3861(00)00643-1

[42] Sanchis A., Prolongo M. G., Salom C., Masegosa R. M.: Melting behavior, miscibility, and hydrogenbonded interactions of poly( $\varepsilon$-caprolactone)/poly(4hydroxystyrene-co-methoxystyrene) blends. Journal of Polymer Science Part B: Polymer Physics, 36, 95104 (1998).

DOI: 10.1002/(SICI)1099-0488(19980115)36:1<95:: AID-POLB11>3.0.CO;2-9

[43] Takayanagi M., Yoshino M., Minami S.: State of crystallization of polyethylene terephthalate determined by the viscoelastic absorptions. Journal of Polymer Science, 61, 7-10 (1962).

DOI: $10.1002 /$ pol.1962.1206117129

[44] Laredo E., Grimau M., Müller A., Bello A., Suarez N.: Influence of aging and crystallinity on the molecular motions in bisphenol-A polycarbonate. Journal of Polymer Science Part B: Polymer Physics, 34, 28632879. (1996).

DOI: $10.1002 /(\mathrm{SICI}) 1099-0488(199612) 34: 17<2863:$ : AID-POLB2>3.0.CO;2-S

[45] Zuo F., Keum J. K., Chen X., Hsiao B. S., Chen H., Lai S-Y., Wevers R., Li J.: The role of interlamellar chain entanglement in deformation-induced structure changes during uniaxial stretching of isotactic polypropylene. Polymer, 48, 6867-6880 (2007).

DOI: $10.1016 /$ j.polymer.2007.08.065

[46] Cheng S. Z. D., Wu Z. Q., Wunderlich B.: Glass transition and melting behavior of poly(thio-1,4-phenylene). Macromolecules, 20, 2802-2810 (1987).

DOI: $10.1021 / \mathrm{ma} 00177 \mathrm{a} 028$

[47] Parizel N., Lauprétre F., Monnerie L.: N.m.r. and d.s.c. investigations of the miscibility of poly(methyl methacrylate)/poly(ethylene oxide) blends. Polymer, 38, 3719-3725 (1997). DOI: $10.1016 / \mathrm{S} 0032-3861(96) 00952-4$

[48] Asano A., Takegoshi K., Hikichi K.: Solid-state NMR study of miscibility and phase-separation of polymer blend: polycarbonate/poly(methyl methacrylate). Polymer Journal, 24, 555-562 (1992).

DOI: $10.1295 /$ polymj. 24.555

[49] Lin R-H., Woo E. M., Chiang J. C.: A solid-state ${ }^{13} \mathrm{C}$ NMR study on phase heterogeneity in the miscible blend of amorphous poly(benzyl methacrylate) with semicrystalline poly(ethylene oxide). Polymer, 42, 4289-4297 (2001).

DOI: $10.1016 / \mathrm{S} 0032-3861(00) 00671-6$ 